\title{
TECHNOLOGY EVOLUTION AND ADVANCES IN FISHERIES ACOUSTICS
}

Dezhang Chu

NOAA National Marine Fisheries Service, Northwest Fisheries Science Center, 2757 Montlake Blvd. E., Seattle, WA 98112, USA., dezhang.chu@noaa.gov

Follow this and additional works at: https://jmstt.ntou.edu.tw/journal

Part of the Aquaculture and Fisheries Commons

\section{Recommended Citation}

Chu, Dezhang (2011) "TECHNOLOGY EVOLUTION AND ADVANCES IN FISHERIES ACOUSTICS," Journal of Marine Science and Technology. Vol. 19: Iss. 3, Article 2.

DOI: $10.51400 / 2709-6998.2188$

Available at: https://jmstt.ntou.edu.tw/journal/vol19/iss3/2

This Research Article is brought to you for free and open access by Journal of Marine Science and Technology. It has been accepted for inclusion in Journal of Marine Science and Technology by an authorized editor of Journal of Marine Science and Technology. 


\section{TECHNOLOGY EVOLUTION AND ADVANCES IN FISHERIES ACOUSTICS}

Acknowledgements

The author would like to thank my colleagues Drs. Nick Tolimieri and Aimee Keller, and Larry Hufnagle for their useful comments and suggestions to the manuscript. 


\title{
TECHNOLOGY EVOLUTION AND ADVANCES IN FISHERIES ACOUSTICS
}

\author{
Dezhang Chu*
}

Key words: sonar, fisheries acoustics, echosounders, technology.

\begin{abstract}
Application of sonar technology to fisheries acoustics has made significant advances over recent decades. The echosounder systems evolved from the simple analog single-beam and single-frequency systems to more sophisticated digital multi-beam and multi-frequency systems. In this paper, a brief review of major technological advances in fisheries acoustics is given, as well as examples of their applications.
\end{abstract}

\section{INTRODUCTION}

Use of active sonar (sound navigation and ranging) as a primary tool to explore oceans has many advantages compared to conventional biological sampling, such as trawls and nets. First, underwater sound propagates at about $1500 \mathrm{~m} / \mathrm{s}$ and can travel a much larger distance, making it possible to sample a much larger volume in a relatively shorter period of time. Secondly, acoustic measurements are remote, less invasive, and non-extractive. Thirdly, it can provide higher spatial resolution in both horizontal and vertical (or range for down-looking echosounders) directions. In this paper, a review of several major technical advances in fisheries and zooplankton acoustics is given. In Section II, the significant advances in sonar technology are described and the corresponding capability of acoustic characterization and classification is provided. Other technologies, including those currently used and expected to be used in the future, are also described briefly in Section III. Finally, summaries are given in Section IV.

\section{TECHNOLOGICAL EVOLUTION}

A timeline involving major technology milestones in fisheries acoustics is illustrated in Fig. 1, where the years corresponding to the milestone events are approximate. These events will be described accordingly in this section. More detailed

Paper submitted 04/14/10; revised 05/07/10; accepted 06/11/10. Author for correspondence: Dezhang Chu (e-mail:dezhang.chu@noaa.gov).

*NOAA National Marine Fisheries Service, Northwest Fisheries Science Center, 2757 Montlake Blvd. E., Seattle, WA 98112, USA.

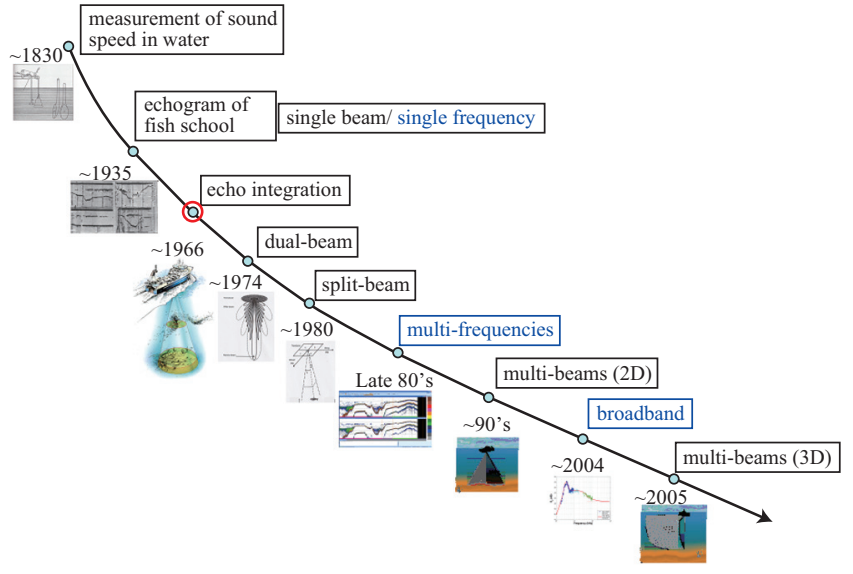

Fig. 1. Chronological events that mark the milestones of acoustic technology advances in fisheries acoustics.

information regarding some of these events have been provided elsewhere $[15,67]$.

\section{Application in Early Days (before WWII)}

The earliest measurement of sound speed in water was performed almost two hundred years ago in Lake Geneva, Switzerland and reported by Colladon and Strum [18]. The sound speed in water was estimated to be about $1435 \mathrm{~m} / \mathrm{s}$. About a hundred years later, use of echo as a sounding technology to measure the bottom depth was reported in 1920's [1]. As early as in the late 20 's to early 30 's of the $20^{\text {th }}$ century, many publications reported the applications of active sonar technology in fisheries research for the detection of fish and zooplankton aggregations [44, 49, 63, 76]. After WWII, rapid advances in techniques helped the application of sonar to fisheries acoustics significantly. The discovery of the deep scattering layer (DSL.) resulting from echoes from various marine organisms provided a fresh vision of the oceans $[6,10,38,45]$. Acoustic surveys in fishery applications became realistic starting in the early 1940's [77], and were conducted more frequently and routinely afterwards $[3,7,20]$. During this period, the sonar systems were simple and primitive, and primarily consisted of a single beam (channel) with a single narrow band frequency, a simple pulse-echo system. The outputs were analog and the standard outputs were graphs plotted on paper $[2,76]$. All of the efforts during this period of time that involved using acoustic 
instruments for fisheries survey were not quantitative. However, echo counting ability of the system enabled some degree of quantitative measurements when the fish school is shallow and dispersed [7].

\section{Echo-Integration Technology}

In the late 1960's, as the revolution in computer science started to impact almost every branch of science, technology and our daily life, digital technology began to be applied to oceanographic instruments $[46,65]$. The digital technology allowed scientists to apply more sophisticated signal processing techniques to post-process the recorded raw echo data. One of the most important milestones in terms of data processing was the introduction of the echo-integration technique [66], which takes advantages of randomness of the scattering targets. It was used successfully in many survey cruises in the late 60 's and in 70's to count fish [58], to estimate fish abundance $[4,37]$, or to estimate the variance of the echo-integration technology [9]. Echo-integration is essentially an integration of echo intensity over a specified range (time) window. The received intensity can be expressed as:

$$
\begin{aligned}
& \bar{I}_{r}(r)=\frac{1}{V_{\text {ins }} \rho_{w} c_{w}}\left\langle\int_{V_{\text {ins }}} \sum_{k} \sum_{k^{\prime}} p_{r}\left(\vec{r}_{k}\right) p_{r}^{*}\left(\vec{r}_{k^{\prime}}\right) d V\right\rangle \\
& =\frac{1}{V_{\text {ins }} \rho_{w} c_{w}} \iiint_{V_{\text {ins }}} \sum_{k} \sum_{k^{\prime}}\left\langle p_{r}\left(\vec{r}_{k}\right) p_{r}^{*}\left(\vec{r}_{k^{\prime}}\right)\right\rangle r^{2} \sin \theta d \theta d \phi d r \\
& =\frac{1}{V_{\text {ins }} \rho_{w} c_{w}} \iiint_{V_{\text {iss }}}(\underbrace{\sum_{k}\left\langle\left|p_{r}\left(\vec{r}_{k}\right)\right|^{2}\right\rangle}_{\text {incoherent }}+\underbrace{\sum_{k} \sum_{k^{\prime} \neq k}\left\langle p_{r}\left(\vec{r}_{k}\right) p_{r}^{*}\left(\vec{r}_{k^{\prime}}\right)\right\rangle}_{\text {coherent }}) r^{2} \sin \theta d \theta d \phi d r
\end{aligned}
$$

where $p_{r}\left(\vec{r}_{k}\right)$ is the received acoustic pressure (complex value) of the $k^{\text {th }}$ target at range $\vec{r}_{k}$ within the insonified sample volume $V_{i n s}, \rho_{w}$ and $c_{w}$ are density of and sound speed in seawater, respectively, and $(r, \theta, \phi)$ are the position variables in spherical coordinates. If we assume the targets are randomly distributed in the sample volume (assume a stochastic process), the coherent component (the second term in the parenthesis) is considerably smaller than the incoherent component (the first term in the parenthesis), hence can be ignored. This is especially true for high frequency echosounder systems $(k d>>1$, where $k$ is the acoustic wave length and $d$ is the average separation between adjacent fish within the fish aggregation). This is the essence of echo-integration. The incoherent component is a linear combination of the backscattering energy from individual targets, manifesting the well known linearity principle in echo-integration [29]:

$$
\bar{I}_{r}(r) \propto n(r) \bar{\sigma}_{b s}(r),
$$

where $\bar{\sigma}_{b s}$ is the average differential backscattering cross section at range $r$ and $n(r)$ is the number of scatterers within the specified sample range $[r-\Delta / 2 r+\Delta / 2]$, where $\Delta$ is the distance spanned by the transmit pulse duration. Since $\bar{\sigma}_{b s}$ can be determined either ex situ, where the animals were either tethered or caged $[61,70,71]$, or in situ, where we need to know the precise information on target position, which requires better technologies to locate the targets, we can estimate the abundance of the targets, $n(r)$, at different ranges.

A quantity that is used extensively in fisheries acoustics, as well as in other sonar applications, is the target strength, defined as the equivalence of the differential backscattering cross section compared with $1 \mathrm{~m}^{2}[16,83]$ :

$$
T S=10 \log _{10} \sigma_{b s} \quad \text { re } 1 \mathrm{~m}^{2}
$$

The echo-integration technology was a major milestone in transforming the qualitative acoustic fisheries application in early days to the modern quantitative fisheries acoustic surveys as indicated in Fig. 1 (red circle), i.e. from observing fish or zooplankton aggregations to estimating abundance/biomass of fish or zooplankton acoustically. It allows scientists to infer the biological quantities, such as abundance or biomass, from the acoustically measured quantities. To perform such a conversion correctly, we need to know the average differential backscattering cross section $\left(\sigma_{b s}\right)$, or target strength $(T S)$ of fish species of interest. This requirement motivated scientists and engineers to develop new technologies for fish target strength measurements.

\section{Acoustic Systems with Multiple Beams}

To obtain accurate target strength measurements, either for acoustic system calibration or for directly estimating the target strength of animals of interest, we need to know the exact location of the animal within the beam since the echo amplitude of any target within the acoustically insonified volume is a function of the target position in the beam. A number of acoustic sensing technologies, such as dual-, split-, and multibeam, have been developed to measure target strength from individual targets and some other acoustic quantities (volume backscattering strength, nautical area scattering coefficient, etc.). These technologies differ from those using echo statistics to infer the target strength indirectly $[19,28,35]$.

\section{1) Dual-Beam Systems}

The dual-beam technique was one of the techniques introduced to fisheries acoustics in the early 1970's to estimate the polar-angle measured from the beam axis of an individual target within the acoustic beam [25], facilitating the measurement of target strength either in situ or ex situ. It takes advantage of the beampattern differences between two independent transducers, one with a wide beamwidth and the other with a narrow beamwidth [24, 25] (Fig. 2(a)). The ratio of the backscattering intensities of the echoes from the wide and narrow beam transducers is used to determine the polar-angle of a single target [67]. The dual-beam technology uses only 

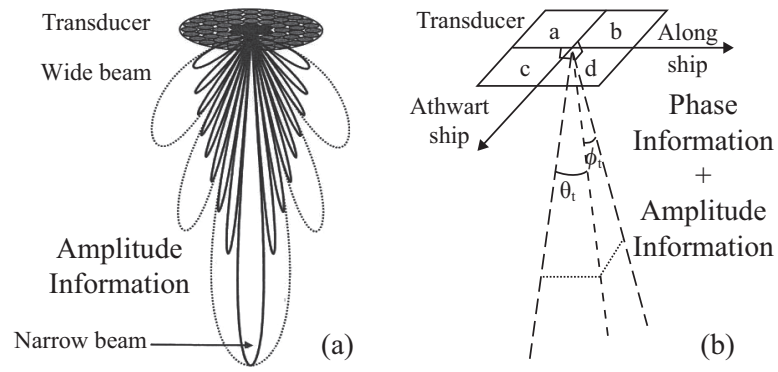

Fig. 2. Conceptual illustrations of (a) dual-beam and (b) split-beam acoustic systems. The drawings are taken from Simmonds and MacLennan [67] with permission.

the information of amplitude or intensity with no phase information, and it can determine only two of three parameters in the spherical coordinates, i.e. $(r, \theta)$ out of $(r, \theta, \phi)$ (Fig. 2). For a circular transducer, the beampattern is independent of the azimuth angle, and hence two parameters $(r, \theta)$ are adequate for target strength measurement of any scattering object or target in the acoustic beam $[78,86]$.

\section{2) Split-Beam Systems}

A different technique, the split-beam technique was introduced to ocean acoustics soon after the dual-beam technology became reality [8], although its application to fisheries acoustics started somewhat later $[26,27,32,56]$. In contrast to a dual-beam system, a split-beam system uses not only the amplitude information, but also the phase information. It uses a so called "interferometry" technique in which it takes advantage of the phase differences between adjacent transducer quadrants [56] (Fig. 2(b)). The phase difference is the function of the acoustic wavenumber $(k)$, the distance between the "acoustic center of mass" of adjacent quadrants, and the angle of target relative to the acoustic beam axis of the transducer. All four quadrants function as transmitters and transmit simultaneously, while they receive the backscattered signals independently, forming four beams with two beams perpendicular to the other two. The target location can be uniquely and accurately (after careful calibration) determined [15, 67, $75,84]$. Through analysis of system performance as a function of signal-to-noise ratio and angular location of the target, Ehrenberg [26] found that the split-beam systems have a superior performance compared to the dual-beam systems. Currently, the split-beam technology is still a standard technique used in many commercial and scientific fisheries acoustic surveys worldwide, and this technology marks a major advance in acoustic technology (Fig. 1).

\section{3) Multi-Beam Systems}

Both dual-beam and split-beam systems can resolve only one target at each range increment. If there is more than one target present in the acoustic beam at the same range (time), echoes from different targets will add coherently. In such a case, neither a dual-beam nor a split-beam system can determine the angular locations of the targets correctly. Since echoes from different targets interfere with each other and produce a combined complex quantity (phase and amplitude), the estimated target location is similar to the geometric center of the insonified targets (i.e. the mean phase reflects the "center of mass"). However, in some cases, the inferred location could be outside of the region that bounds the involved targets. This phenomenon results from the so called "baseline decorrelation" [43, 55] or "coincidence echo" [30] when the phase is close to $\pi(\mathrm{rad})$ or $180^{\circ}$. Multi-beam sonars, on the other hand, consist of multi-transducer elements and can resolve multiple targets at the same range simultaneously. Multi-beam sonars are based on the concept of applying coherent summation over all or a subset of array elements $[15,67,83]$, and has been used widely in radar phase-array applications $[47,48,64]$. An N-element linear-array multi-beam can form N-1 independent beams in $2 \mathrm{D}$, hence capable of resolving maximum of N-1 targets at the same range.

Although the application of multi-beam technology to fisheries acoustics began as early as in the late 70's [60], the technology became widely accepted in the 1990's when significant improvements occurred in both hardware and software technology $[17,31,33,34,57,59]$. The number of applications of multi-beam sonars in fisheries acoustics have increased significantly since the Simrad ME70 echosounder and MS70 multi-beam sonar became commercially available $[21,22,51,52,62,79,80]$. There are two types of multi-beam systems: pseudo 3D and true 3D.

A pseudo 3D multi-beam system collects a true 2D image in the athwartship plane for each ping and then forms a 3D volumetric image by combining a series of pings along the ship track (Fig. 3). This type of echogram is not a true 3D image but if fish schools move at a much slower speed than that of the ship ( 11 knots), as they usually do, the derived 3D images of fish school or aggregation will be reasonably representative and informative. Currently, most commercially available multi-beam systems are of this type, such as Simrad SM20 (formerly SM2000), Simrad ME70, and Reson SeaBat 7000 and 8000 series.

A true 3D multi-beam system is one that images a 3D volume with one ping, such as Simrad MS70, which has a total of 500 beams $(25 \times 20)$ as illustrated in Fig. 4 [52, 62]. A true 3D multi-beam sonar system like MS70 enables scientists to image the instantaneous shape of a fish school and track its change as a function of time, which can provide more accurate morphological information on the shape and size dynamics of fish schools or aggregations. Although this system is currently used, its application to actual acoustic survey still requires further research. However, the potential of such a system is enormous and we expect its full survey operation to become reality in the near future (Fig. 1).

\section{Acoustic Systems with Multiple Frequencies}

Concurrent with the advances in number of beams for sonar or echosounder systems, there has been a parallel development in terms of number of frequencies. 


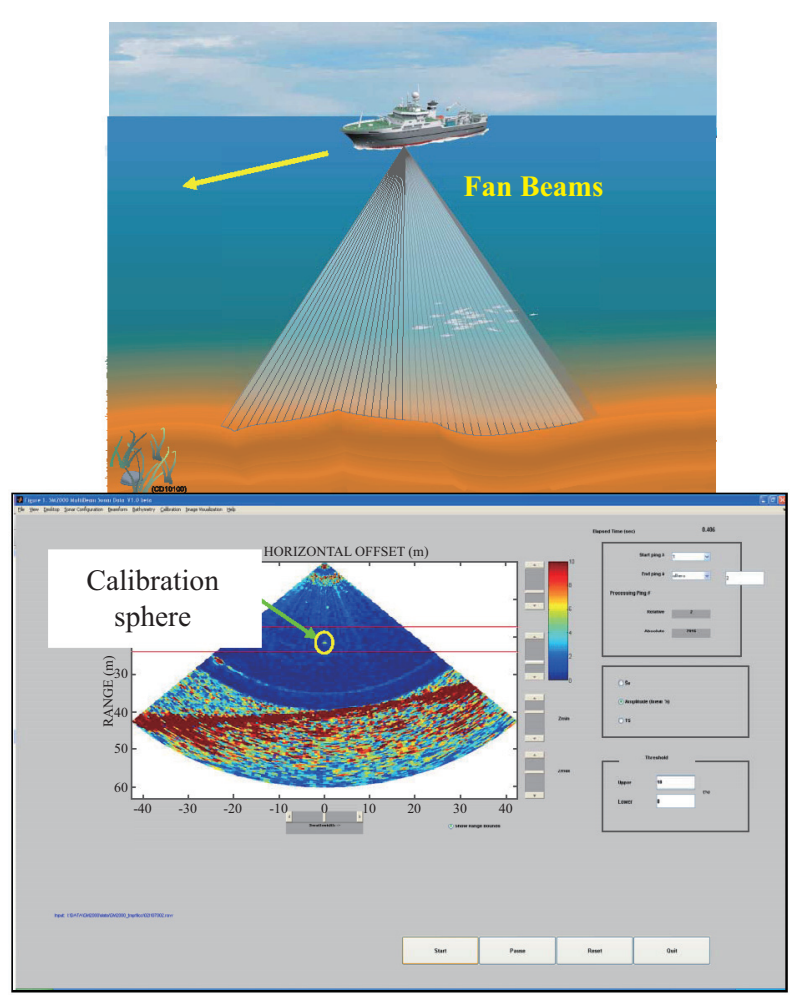

Fig. 3. Illustration of a 2D multi-beam echosunder, Simrad ME70 (top), and a Simrad SM20 image display of one ping during a calibration (bottom), where the calibration sphere is an aluminum sphere with a diameter of $38 \mathrm{~mm}$.

\section{1) Multiple Discrete Frequency Systems}

The strong frequency dependence of signals backscattered by marine animals has been a known phenomenon for many decades. Technology evolution from single frequency to (narrow band) multiple frequency systems (Fig. 1) provided scientists with additional capability to characterize or classify the scattering targets $[12,14,39,40,41,42]$.

Since both multi-frequency and multi-beam technologies have developed concurrently, the combination of two types of technologies is natural. For example, the BIOacoustic Sensing Platform And Relay (BIOSPAR) is a dual beam and dual frequency system constructed by the Woods Hole Oceanographic Institution (WHOI) with the acoustic components provided by BioSonics, Inc. [85]. This system has the shape of a spar buoy and carries two down-looking dual-beam transducers, operated at $120 \mathrm{kHz}$ and $420 \mathrm{kHz}$, respectively. It can be deployed as either a moored or a drifting data acquisition system. This system was used successfully to measure the target strengths of more than 40 live individual zooplankton and microneckton [86].

Despite the success of the dual-beam/multi-frequency systems such as BIOSPAR, most hybrid multi-frequency and multi-beam echosounders currently used worldwide are those that integrate the split-beam and multi-frequency technologies. Acoustic survey ships, such as G. O. Sars, (IMR, Norway), NOAA ships Oscar Dyson, Miller Freeman, and Delaware II,

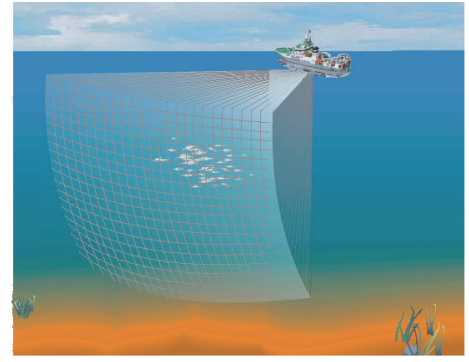

(a)

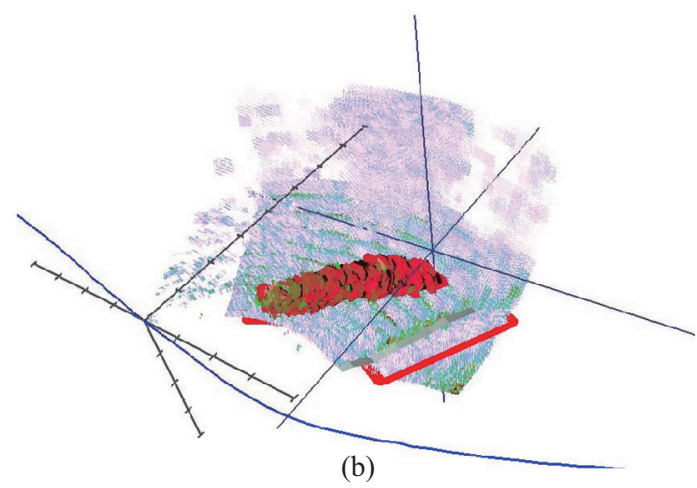

Fig. 4. (a) Illustration of a 3D multi-beam echosunder (Simrad MS70), (b) a herring school mapped by a single ping of the MS70 multibeam sonar system (courtesy of Dr. Korneliussen).

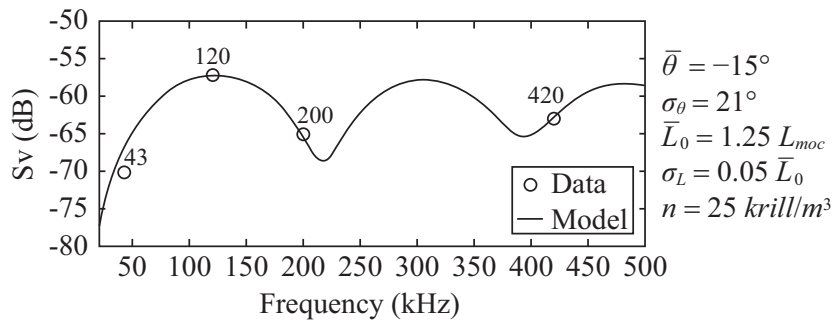

Fig. 5. Comparison of the acoustic backscattering data from Antarctic krill (Euphausia superba) recorded by BIOMAPER II [5] at 43-, 120-, 200-, and $420 \mathrm{kHz}$ on a Southern Ocean GLOBEC cruise in Margerate Bay in 2002. The inverted parameters shown in the legend on the right are obtained with a nonlinear least-square inversion algorithm, where $\bar{\theta}$ and $\sigma_{\theta}$ are the mean and standard deviation of angle of orientation, $L_{m o c}$ is the mean body length of the krill in the aggregation from the MOCNESS sampling [87], $\bar{L}$ and $\sigma_{L}$ are the inverted mean and standard deviation of krill body length, and $n$ is the inverted abundance of the krill aggregation.

are equipped with a number of split-beam echosounders at different frequencies, including all or a subset of 18-, 38-, 70-, 120-, 200-, and $333 \mathrm{kHz}$. Multi-frequency backscattering data can provide more information than a single frequency system $[12,41])$, especially when the transition from Rayleigh scattering to geometric scattering is involved [16]. Fig. 5 shows a comparison between the data and the scattering model inferred from a four-frequency acoustic data set recorded with the BIOMAPER II [5]. The data are from Antarctic krill 
(Euphausia superba) collected during a Southern Ocean GLOBEC cruise in 2002. The theoretical prediction (solid curve) is obtained using the parameters resulting from a nonlinear least-square inversion algorithm [53, 54]. The inverted parameters are given in the figure legend.

\section{2) Broadband or Wideband Systems}

If the multi-frequency systems described in the previous section cover a wide frequency band with a number of discrete frequencies, they can be regarded as broadband or wideband acoustic systems. However, in this paper, we refer to a broadband or wideband system as a system that contains a single transducer that can provide a frequency response of the acoustic scattering over a continuous broad frequency band $[50,73]$. A continuous broadband system allows the study of the impulse response of the acoustic scattering by marine organisms directly [88], the spectral characterization of the scattering by marine animals from different anatomic groups [73, 74], and/or the temporal characterization of these groups using a pulse compression technique [13]. The pulse compression technology not only increases the time domain resolution, which is inversely proportional to the system bandwidth (Figs. $6(\mathrm{a})$ and $6(\mathrm{~b})$ ), but also improves the signal-to-noise ratio (SNR) by a factor of approximately $2 B T$, where $B$ is the bandwidth of the system and $T$ is the pulse duration [82]. The results shown in Fig. 6 are from theoretical simulations. The transmit signal (Fig. 6(a)) is a chirp signal with frequency swept from 0 to $4000 \mathrm{kHz}$ in $100 \mathrm{~ms}$.

\section{OTHER TECHNIQUES}

In addition to the acoustic technologies described in Section II, there are others that have been used for different applications in fisheries acoustics

\section{Sidescan Sonars}

The side-scan sonar is a single-beam acoustic system normally mounted on a towed body with its beam axis perpendicular to the cruise track. The beamwidth is narrow in foreaft direction (alongship), typically $1^{\circ}$, but much wide in the vertical plane (athwartship), typically $40^{\circ}$ [67]. Unlike downlooking echosounders, sidescan sonars form a fan-beam for each ping and, by combining the successive ping, can provide $3 \mathrm{D}$ acoustic images of the water column on both sides of the vessel or towfish $[68,69]$. There are two types of side-scan sonars: one uses amplitude information only, i.e., the backscattering as a function of time or range, and the other uses both phase and amplitude information, i.e., the interferometry technique that is also used for split-beam. It provides not only the backscattering as a function of time or range, but also the direction of arrival (DOA) of fish schools for water column imaging or bathymetry for seafloor mapping [75].

\section{Scanning Sonars}

Scanning sonars allow the sonar head to rotate mechani-

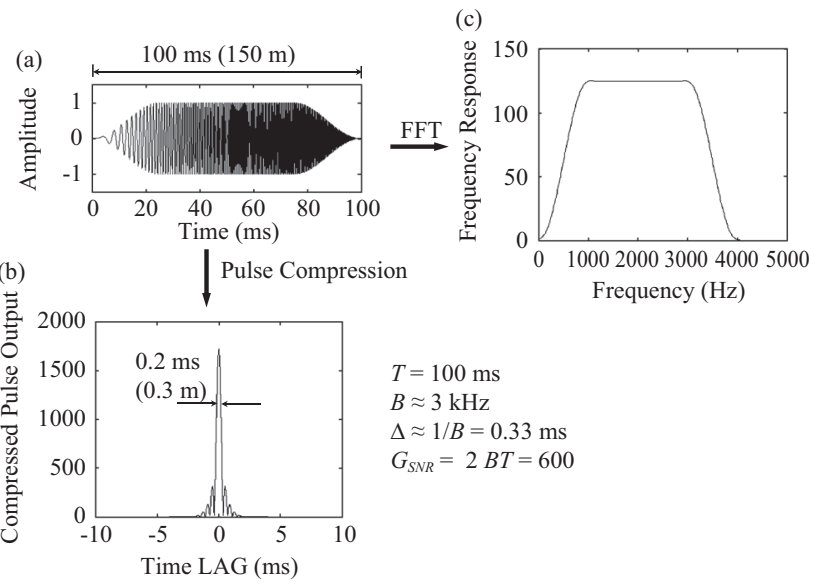

Fig. 6. An example of the acoustic characteristics of a broadband system. (a) a transmit chirp signal, sweeping from 0 to $4 \mathrm{kHz}$ over a time window of $100 \mathrm{~ms}$; (b) compressed pulse output; (c) corresponding frequency response of the time series in (a). The bandwidth $(B)$ of the transmit signal is approximately $3 \mathrm{kHz}$, resulting in a compressed pulse output resolution of $0.33 \mathrm{~ms}$ resolution in the time domain and $0.5 \mathrm{~m}$ in the spatial domain, assuming a 1500 $\mathrm{m} / \mathrm{s}$ sound speed. The gain in signal-to-noise can be determined by $G_{s n r} \approx 2 B T=600$, or about $28 \mathrm{~dB}$, where $T$ is the pulse duration $(100 \mathrm{~ms})$. Units on the vertical axes of all three plots are linear quantities in arbitrary scale.

cally in either $1 \mathrm{D}$ or $2 \mathrm{D}$, providing either $2 \mathrm{D}$ or $3 \mathrm{D}$ images [67]. This type of acoustic instrument is normally a singlebeam device and often used for fish school searching. Such systems have a highly directional pencil beam, capable of resolving small features such as small aggregations of fish and zooplankton, as well as individual targets depending on the range and the size of target. Since mechanical rotation requires more time, scanning sonars work best when targeted fish or zooplankton aggregations are "static".

\section{Acoustic Doppler Current Profiler (ADCP)}

ADCPs are commonly used for mapping the currents in the oceans but can also be used for mapping fish or zooplankton schools, as long as the size of the fish school is much larger than the boundary of the four ADCP beams [23, 89]. This type of instruments consists of four down-looking beams, each having a tilt angle relative to the vertical direction. The phase differences between beams reflect the moving speed of the target of interest (fish, zooplankton, or current), an acoustic Doppler effect [23].

\section{Acoustic Lens}

Acoustic camera or acoustic lens refers to an acoustic system that utilizes a technique similar to that of optical cameras. It can be operated in dark or turbid water where optical cameras are unable to provide images with satisfactory quality. There are two important features for such systems. First, it has to be in the geometric scattering region, i.e. the physical size of the acoustic lens must be much greater than the acoustic wave 
length, so the ray theory can be applied. Second, it is a multibeam system but its beamforming operation is performed automatically when the backscattered acoustic "rays" enter the acoustic lens. The acoustic lens uses a special fluid in which the sound speed is different from that in the surrounding water. The acoustic rays are refracted due to sound speed difference between two fluids and focused to an acoustic array, forming an acoustic "video" image for each ping. An "acoustic movie" can be obtained with a series of pings recorded continuously [67]. An example of this type of instrument is the Dual frequency IDentification SONars (DIDSON) system.

\section{Parametric Sonars}

Parametric sonars utilize the nonlinearity of the sonar system to extract the energy leaked from the quadratic component [36]. Although the efficiency of parametric sonars is low (could be less than $1 \%$ ), they can provide very directional acoustic insonification at much lower frequencies compared to the physical dimension or aperture of the sonar head. Such a characteristic could be very useful for studying fish with swimbladders since swimbladders resonate acoustically at very low frequencies ( $1 \mathrm{kHz}$ or lower). The advantage of measuring fish scattering at or near resonance frequencies is that the acoustic backscattering is almost independent of fish orientation, making estimates of abundance easier and more accurate.

\section{SUMAARY}

In this paper, a summary of the evolution of sonar technologies used in fisheries acoustic is presented. Fig. 1 provides a chronological depiction of the advances in technology advances. The echo-integration technology played a key role for transforming qualitative acoustic measurements to quantitative measurements. At the same time, other technologies have resulted in significantly improving data quality in terms of resolution and information content and extraction.

It should be pointed out that there are many important scientific and engineering issues associated with the application of sonar techniques to the fisheries acoustics field that are not discussed in this paper, such as system calibration, error analysis, and operation engineering, but the major milestones in acoustic technologies have been addressed here.

\section{ACKNOWLEDGMENTS}

The author would like to thank my colleagues Drs. Nick Tolimieri and Aimee Keller, and Larry Hufnagle for their useful comments and suggestions to the manuscript.

\section{REFERENCES}

1. Anon, "Echo sounding," Nature, Vol. 115, pp. 689-690 (1925).

2. Anon, "Forsokene med ckkolodd ved Brislingfisket (Trail with an echosounder during the sprat fishery)," Tiddsskrift for Hermetikindustri (Bulletin of the Canning Industry), July, pp. 222-223 (1934). (in Norwegian)
3. Anon, "Report of the third meeting of the Atlantic-Scandian herring working group," ICES, C.M. 1965/161 (Mimeo) (1965).

4. Anon, "Preliminary report of the international 0-group fish survey in the 3. Barents sea and adjacent waters August/September 1967," ICES, C.M. 1967/H:31 (1967).

5. Austin, T. C., Arthur, R. I., Stanton, T. K., and Wiebe, P. H., "BIOMAPER-II: A towed bio-acoustic survey system for zooplankton and fish assessment," Proceedings of the Ocean Community Conference '98, Marine Technology Society, Baltimore, MD, pp. 933-938 (1998).

6. Backus, R. H., "A bibliography pertaining the deep scattering layer and the fishery applications of the echo sounding and ranging," WHOI Technical Report, No. 53-42 (1953).

7. Balls, R., "Herring fishing with the echometer," Journal du Conseil Permanent International pour l'Exploration de la Mer, Vol. 15, pp. 192 206 (1948).

8. Barry, W. A. and Jackson, D. R., "Split-beam towed sonar for ocean acoustic measurements," OCEAN'80 An International Forum on Ocean Engineering in the 80's, Seattle, WA, pp. 267-271 (1980).

9. Bodholt, H., "Variance error in echo integrator output," Rapports et Proces-Verbaux des Reunions des Conseil International pour l'Exploration de la Mer, Vol, 170, pp. 196-204 (1977).

10. Chapman, W. M., "The wealth of the ocean," Scientific Monthly, Vol. 64, pp. 192-197 (1947)

11. Chu, D., Baldwin, K. C., Foote, K. G., Li, Y., Mayer, L. A., and Melvin, G. D., "Multibeam sonar calibration: target localization in azimuth," OCEANS, 2001. MTS/IEEE Conference and Exhibition, Honolulu, Vol. 4, pp. 2506-2510 (2001).

12. Chu, D., Foote, K. G., and Stanton, T. K., "Further analysis of target strength measurements of Antarctic krill at $38 \mathrm{kHz}$ and $120 \mathrm{kHz}$ : Comparison with deformed cylinder model and inference of orientation distribution," Journal of the Acoustical Society of America, Vol. 93, pp. 2985-2988(L) (1993).

13. Chu, D. and Stanton, T. K., "Application of pulse compression techniques to broadband acoustic scattering by live individual zooplankton," Journal of the Acoustical Society of America, Vol. 104, pp. 39-55 (1998).

14. Chu, D., Stanton, T. K., and Wiebe, P. H., "Frequency dependence of sound backscattering from live individual zooplankton," ICES Journal of Marine Science, Vol. 49, pp. 97-106 (1992).

15. Chu, D. and Wiebe, P. H., "Application of sonar techniques to oceanographic-biological surveys," Current Topics in Acoustical Research, Vol. 3, pp. 1-25 (2003).

16. Clay, C. S. and Medwin, H., Acoustical Oceanography: Principles and applications, John Willy \& Sons, New York, pp. 184-194 (1977).

17. Cochrane, N. A., Li, Y., and Melvin, G. D., "Quantification of a multibeam sonar for fisheries assessment applications," Journal of the Acoustical Society of America, Vol. 114, pp. 745-758 (2003).

18. Colladon, J. D. and Strum, J. K. F., "The compression of liquids" (in French), Annales de Chimie et de Physique, Series 2 (36), part IV, Speed of sound in liquids, pp. 236-257 (1827).

19. Craig, R. E. and Forbes, S. T., "Design of a sonar for fish counting," Fiskeridirektoratets Skrifter Serie Havundersokelser, Vol. 15, pp. 210219 (1969).

20. Cushing, D. H., "Echo-survey of fish,” Journal du Conseil Permanent International pour l'Exploration de la Mer, Vol. 18, pp. 45-60 (1952).

21. Cutter, G. R. and Demer, D. A., "Accounting for scattering directivity and fish behaviour in multibeam-echosounder surveys," ICES Journal of Marine Science, Vol. 64, pp. 1664-1674 (2007).

22. Cutter, G. R., Renfree, J. S., Cox, M. J., Brierley, A. S., and Demer, D. A., "Modelling three-dimensional directivity of sound scattering by Antarctic krill: progress towards biomass estimation using multibeam sonar," ICES Journal of Marine Science, Vol. 66, pp. 1245-1251 (2009).

23. Demer, D. A., Barange, M., and Boyd, A., "Measuring fish school velocities with an acoustic Doppler current profiler," Fisheries Research, Vol. 47, pp. 201-214 (2000).

24. Drew, A. W., "Initial results from a portable dual-beam sounder for in situ measurements of target strength of fish," OCEAN'80 An International 
Forum on Ocean Engineering in the 80's, Seattle, WA, pp. 376-380 (1980).

25. Ehrenberg, J. E., "Two applications for a dual-beam transducer in hydroacoustic fish assessment systems," Proceedings of the OCEAN'74 IEEE International Conference on Engineering in the Ocean Environmental, Halifax, Nova Scotia, Aug. 21-23, Vol. 1, pp. 152-155 (1974).

26. Ehrenberg, J. E., "A comparative analysis of in situ methods for directly measuring the acoustic target strength of individual fish," IEEE Journal of Oceanic Engineering, Vol. 4, pp. 141-152 (1979).

27. Ehrenberg, J. E., “A review of in situ target strength estimation technique," ICES/FAO Symposium on Fisheries Acoustics, Bergen, Norway, June 21-24, pp. 85-90 (1982).

28. Ehrenberg, J. E. and Lytle, D.W., "Some signal processing techniques for reducing the varience in acoustic stock abundance estimates," Rapports et Proces-Verbaux des Reunions des Conseil International pour l'Exploration de la Mer, Vol. 170, pp. 205-213 (1977).

29. Foote, K. G., "Linearity of fisheries acoustics, with addition theorems," Journal of the Acoustical Society of America, Vol. 73, pp. 1932-1940 (1983).

30. Foote, K. G., "Coincidence echo statistics," Journal of the Acoustical Society of America, Vol. 99, pp. 266-271 (1996).

31. Foote, K. G., Chu, D., Hammar, T. R., Baldwin, K. C., Mayer, L. A., Hufnagle, L. C., and Jech, J. M., "Protocols for calibrating multibeam sonar," Journal of the Acoustical Society of America, Vol. 117, pp. 2013 2027 (2005).

32. Foote, K. G., Kristensen, F. H., and Solli, H., "Trial of a new, split-beam echo sounder," ICES Council Meeting 1984 (collected papers), ICES, Copenhagen, Denmark, 15 pp (1984).

33. Gerlotto, F., Freon, P., Soria, M., Cottais, P-H., and Ronzier, L., "Exhausitive observation of 3D school structure using multibeam side scan sonar: Potential use for school classification, biomass and behavior studies," ICES Council Meeting Papers, ICES, Copenhagen, Denmark, 12 pp., or ICES C.M. 1994/B:26 (1994).

34. Gerlotto, F., Soria, M., and Fréon, P., "From two dimensions to three: the use of multibeam sonar for a new approach in fisheries acoustics," Canadian Journal of Fisheries and Aquatic Sciences, Vol. 56, pp. 6-12 (1999).

35. Goddard, G. C. and Welsby, V. G., "Statistical measurements of the acoustic target strength of live fish," Rapports et Proces-Verbaux des Reunions des Conseil International pour l'Exploration de la Mer, Vol. 170, pp. 70-73 (1977).

36. Godø, Q. R., Foote, K. G., Dybedal, J., Tenningen, E., and Pate, R., "Detecting Atlantic herring by parametric sonar," Journal of the Acoustical Society of America, Vol. 127, pp. EL153-EL159 (2010).

37. Haug, A. and Nakken, O., "Echo abundance indices of 0-group fish in the Barents sea, 1965-1971," Rapports et Proces-Verbaux des Reunions des Conseil International pour l'Exploration de la Mer, Vol. 170, pp. 259-264 (1977).

38. Hersey, J. B. and H. B. Moore, "Progress report on scattering layer observations in the Atlantic Ocean," Transactions, American Geophysical Union, Vol. 29, pp. 341-354 (1948).

39. Holliday, D. V., "Resonance structure in echoes from schooled pelagic fish," Journal of the Acoustical Society of America, Vol. 51, pp. 13221331 (1971).

40. Holliday, D. V., "The use of swimbladder resonance in the sizing of schooled pelagic fish," Rapports et Proces-Verbaux des Reunions des Conseil International pour l'Exploration de la Mer, Vol. 189, pp. 130-135 (1977).

41. Holliday, D. V., Pieper, R. E., and Kleppel, G. S., "Determination of zooplankton size and distribution with multi-frequency acoustic technology," Journal du Conseil Internaitonal pour l'Exploration de la Mer, Vol. 46, pp. 52-61 (1989)

42. Jech, J. M. and Michaels, W. L., "A multifrequency method to classify and evaluate fisheries acoustics data," Canadian Journal of Fisheries and Aquatic Sciences, Vol. 63, pp. 2225-2235 (2006).

43. Jin, G., and Tang, D., "Uncertainties of differential phase estimation associated with interferometric sonars," IEEE Journal of Oceanic Engineering, Vol. 21, pp. 53-62 (1996).
44. Johns, W., "Das Echolot in der Fischerei (The echo sounding in fisheries)," Der Fischmarkt, Vol. 10, pp. 256-258 (1934).

45. Johnson, M. W., "Sound as a tool in marine ecology, from data on biological noises and the deep scattering layer," Journal of Marine Research, Vol. 7, pp. 443-458 (1948).

46. Jones, E. E., and Asato, L. T. M., "Recent data acquisition system development aboard NOAA ships," IEEE '71 Conference on Engineering in the Ocean Environmental, San Diego, California, pp. 109-112 (1971).

47. Keeley, J. R., Comparison of wave measurements from a synthetic array radar, Marine Environmental Data Services Branch, Department of Fisheries and Oceans, Ottawa, Ontario (1982).

48. Kendig, P. M., “Advanced transducer developments," In: Albers, V. M. (Ed.), Underwater Acoustics, Vol. 2, Chapter 2 (1967).

49. Kimura, K., "On the detection of fish-groups by an acoustic method," Journal of the Imperial Fisheries Institute, Toyko, Vol. 24, pp. 41-45 (1929).

50. Kjærgaard, N., Kirkegaard, L. B., and Lassen, H., "Broadband analysis of acoustical scattering by individual fish," Rapports et Proces-Verbaux des Reunions des Conseil International pour l'Exploration de la Mer, Vol. 189, pp. 370-380 (1990).

51. Korneliussen, R. J., Diner, N., Ona, E., Berger, L., and Fernandes, P. G., "Proposals for the collection of multifrequency acoustic data," ICES Journal of Marine Science, Vol. 65, pp. $982-994$ (2008).

52. Korneliussen, R. J., Heggelund, Y., Eliassen, I. K., Øye, O. K., Knutsen, T, and Dalen, J., "Combining multibeam-sonar and multifrequencyechosounder data: examples of the analysis and imaging of large euphausiid schools," ICES Journal of Marine Science, Vol. 66, pp. 991-997 (2009).

53. Lawson, G. L., Wiebe, P. H., Stanton, T. K., and Ashjian, C. J., "Euphausiid distribution along the Western Antarctic Peninsula — Part A: Development of robust multi-frequency acoustic techniques to identify euphausiid aggregations and quantify euphausiid size, abundance, and biomass," Deep-Sea Research II, Vol. 55, pp. 412-431 (2008a).

54. Lawson, G. L., Wiebe, P. H., Stanton, T. K., and Ashjian, C. J., "Euphausiid distribution along the Western Antarctic Peninsula - Part B: Distribution of euphausiid aggregations and biomass, and associations with environmental features," Deep-Sea Research II, Vol. 55, pp. 432-454 (2008b).

55. Li, F. K. and Goldstein, R. M., "Studies of multibaseline spaceborne interferometric synthetic aperture sonars," IEEE Transactions on Geoscience Remote Sensing, Vol. 28, pp. 88-97 (1990).

56. MacLennan, D. N. and Svellingen, I., "Simple calibration of a split-beam echo-sounder," ICES Council Meeting 1986 (collected papers), ICES, Copenhagen, Denmark, 11 pp (1986).

57. Mayer, L., Li, Y., and Melvin, G., "3D visualization for pelagic fisheries research and assessment," ICES Journal of Marine Science, Vol. 59, pp. 216-225 (2002).

58. Midttun, L. and Nakken, O., "Counting of fish with an echo integrator," ICES, C.M. 1968/B:17 (1968)

59. Misund, O. A. and Coetzee, J., "Recording fish schools by multi-beam sonar: potential for validating and supplementing echo-integration recordings of schooling fish," Fisheries Research, Vol. 47, pp. 149-159 (2000).

60. Mross, S., "Fishing with the Atlas 950 panoramic sonar," Fishing News International, Vol. 17, No. 10, pp. 44-45 (1978).

61. Nakken, O. and Olsen, K., "Target strength measurements of fish," Rapports et Proces-Verbaux des Reunions des Conseil International pour l'Exploration de la Mer, Vol. 170, pp. 52-69 (1977).

62. Ona, E., Mazauric, V., and Andersen, L. N., "Calibration methods for two scientific multibeam systems," ICES Journal of Marine Science, 66: 1326-1334 (2009).

63. Ortalla, F., "Sull'impiego degli scandagli acustici a bordo del naviglio da pesca (On echo sounding on board a fishing smack)," Rivista Marittima, May, pp. 525-526 (1927).

64. Provencher, J. H. and Munger, A. D., Circular-array radar antenna: Pencil-beam forming and phasing techniques, Naval Electronics Labo- 
ratory Center, San Diego (1968).

65. Sawyer, G. N. and Butler, J. A., "Computerized acoustic fish assessment system," IEEE '71 Conference on Engineering in the Ocean Environmental, San Diego, California, pp. 41-43 (1971).

66. Scherbino, M. And Truskanov, M. D., "Determination of fish concentration by means of acoustic apparatus," ICES, C.M. 1966/F3, 6 pp (1966).

67. Simmonds, J. and MacLennan, D. N., Fisheries Acoustics: Theory and Practice, $2^{\text {nd }}$ Edition, Blackwell Science Ltd., Oxford, UK, 437 pp (2005).

68. Smith, P. E., "The horizontal dimensions and abundance of fish schools in the upper mixed layer as measured by sonar," Proceedings of the International Symposium on Biological Sound Scattering in the Ocean, March 31-April2, Maury Ocean Science Center, Department of the Navy, Washington, DC (1970).

69. Smith, P. E., "The effect of internal waves on fish school mapping with sonar in the California Current area," Rapports et Proces-Verbaux des Reunions des Conseil International pour l'Exploration de la Mer, Vol. 170, pp. 223-231 (1977).

70. Smith, P. F., "Measurements of the sound scattering properties of several forms of marine life," WHOI Technical Report, No. 51-68 (1951).

71. Smith, P. F., "Further Measurements of the sound scattering properties of several forms of marine organisms," Deep-Sea Research, Vol. 2, pp. 71-79 (1954)

72. Stanton, T. K., "Sound scattering by cylinders of finite length. III. Deformed cylinders," Journal of the Acoustical Society of America, Vol. 86, pp. 691-705 (1989)

73. Stanton, T. K, Chu, D., and Wiebe, P. H., "Sound scattering by several zooplankton groups. I. Experimental determination of dominate scattering mechanisms," Journal of the Acoustical Society of America, Vol. 103, pp. $225-235$ (1998a).

74. Stanton, T. K, Chu, D., and Wiebe, P. H., "Sound scattering by several zooplankton groups. II. Scattering Models," Journal of the Acoustical Society of America, Vol. 103, pp. 236-253 (1998b).

75. Stewart, W. K., Chu, D., Malik, S., Lerner, S. and Singh, H., "Quantitative seafloor characterization using a bathymetric sidescan sonar," IEEE Journal of Oceanic Engineering, Vol. 19, pp. 599-610 (1994).

76. Sund, O., "Echo sounding in fishery research," Nature, Vol. 135, pp. 953 (1935).

77. Tester, A. L., "Use of the echo-sounder to locate herring in British Columbia waters," Journal of the Fisheries Research Board of Canada, Bulletin
No. 63, pp. 21 (1943).

78. Traynor, J. J. and Ehrenberg, J. E., "Fish and standard sphere target strength measurements obtained with a dual-beam and split-beam echo sounding system," Rapports et Proces-Verbaux des Reunions des Conseil International pour l'Exploration de la Mer, Vol. 189, pp. 325-335 (1990).

79. Trenkel, V. M., Mazauric, V., and Berger, L., "The new fisheries multibeam echosounder ME70: description and expected contribution to fisheries research," ICES Journal of Marine Science, 65: 645-655 (2008).

80. Trygonis, V., Georgakarakos, S., and Simmonds, E. J., "An operational system for automatic school identification on multibeam sonar echoes,' ICES Journal of Marine Science, Vol. 66, pp. $935-949$ (2009).

81. Tucker, G. H., "Relation of fishes and other organisms to the scattering of underwater sound," Journal of Marine Research, Vol. 10, pp. 215-238 (1951).

82. Turin, G. L., "An introduction to matched filters," IRE Transactiona on Information Theory, Vol. IT-6, pp. 311-329 (1960).

83. Urick, R. J., Principles of Underwater Sound, $3^{\text {rd }}$ Ed., McGraw-Hill, New York (1983).

84. Warren, J. D., Stanton, T. K., Benfield, M. C., Wiebe, P. H., Chu, D., and Sutor, M., "In situ measurements of acoustic target strengths of gas-bearing siphonophores," ICES Journal of Marine Science, Vol. 58, pp. 740749 (2001)

85. Wiebe, P. H. and Greene, C. H., "The use of high frequency acoustics in the study of zooplankton spatial and temporal patterns," Proceedings of the NIPR Symposium on Polar Biology, Vol. 7, pp. 133-157 (1994).

86. Wiebe, P. H., Greene, C. H., Stanton, T. K., and Burczynski, J., "Sound scattering by live zooplankton and micronecton: Empirical studies with a dual-beam acoustical system," Journal of the Acoustical Society of America, Vol. 88, pp. 2346-2360 (1990).

87. Wiebe, P. H., Morton, A. W., Bradley, A. M., Backus, R. H., Craddock, J. E., Cowles, T. J., Barber, V. A., and Flierl, G. R., "New developments in the MOCNESS, an apparatus for sampling zooplankton and micronekton," Marine Biology, Vol. 87, pp. 313-323 (1985).

88. Zakharia, M. E., "Variations in fish target strength induced by movement: a wideband-impulse experiment," Rapports et Proces-Verbaux des Reunions des Conseil International pour l'Exploration de la Mer, Vol. 189, pp. 398-404 (1990).

89. Zedel, L. and Cyr-Racine, F-Y., "Extracting fish and water velocity from Doppler profiler data," ICES Journal of Marine Science, Vol. 66, pp. 18461852 (2009). 